\title{
OUTCOME STUDY OF TITANIUM AND STAINLESS STEEL ELASTIC NAIL FIXATION OF PAEDIATRIC FRACTURE SHAFT OF FEMUR
}

Saubhik Ray ${ }^{1}$, Ashish Goyal², Ashish Gohiya ${ }^{3}$, Sanjeev Gaur ${ }^{4}$

\section{HOW TO CITE THIS ARTICLE:}

Saubhik Ray, Ashish Goyal, Ashish Gohiya, Sanjeev Gaur, "Outcome Study of Titanium and Stainless Steel Elastic Nail Fixation of Paediatric Fracture Shaft of Femur". Journal of Evolution of Medical and Dental Sciences 2014; Vol. 3, Issue 44, September 15; Page: 10811-10819, DOI: 10.14260/jemds/2014/3409

ABSTRACT: INTRODUCTION: Femoral shaft fractures are common fractures in paediatric age group. There are various methods to treat them. Elastic stable intramedullary nailing is one of them and an established and reliable method for treating these fractures. Ideal treatment of femoral shaft fractures in the age group of 5 to 14 years is still a matter of debate as no consensus has been achieved till now. We have done a study to know whether elastic stable intramedullary nails can be used reliably in this age group. So, purpose of the present study is to evaluate the outcome of titanium and stainless steel elastic nail in paediatric femoral fractures in 5-14 years of age group. METHODS: A group of forty two children with femoral fractures that were treated with elastic nails (which includes both titanium and stainless steel nails- both nail types were of similar design) and outcome was evaluated. Twenty children (16 boys, four girls) in the age group of 5-14 years (average 9.3 years) with femoral shaft fractures (16 closed, two Grade- I and two Grade- II compound) were stabilized with Titanium Elastic Nail (TEN), while twenty-two (16 boys, six girls) in the age group of 5-14 years (average 9.1 years) with femoral shaft fractures (18 closed, two Grade- I and two Grade- II compound) were stabilized with Stainless Steel Elastic Nail (SSEN) between June 2009 and October 2011. A familiar retrograde insertion technique was used. Major complications were defined as malunion with sagittal angulation of $>15^{\circ}$ and coronal angulation of $>10^{\circ}$, nail irritation requiring revision surgery, infection, delayed union, and rod breakage. Minor complications were defined as nail irritation or superficial infection not requiring surgery. RESULTS: Radiological union was achieved in all cases in a mean time of 7.7 weeks (6-12 weeks) in TEN groups while that took 7.9 weeks in SSEN group. Full weight bearing was possible in a mean time of 7.7 weeks (6-12 weeks) in TEN groups and a mean of 7.9 weeks in SSEN group. All cases were assessed by Flynn classification method and outcome scoring system. We noted excellent results in 26 cases (63\%), satisfactory results in 14 cases (33\%), while poor result in 2 cases (4\%) in this study. There were six minor complications such as one superficial cellulitis and one case of implant-related pain and four cases of skin irritation at the nail tip (18\%). Two cases deep infection (both cases are associated with grade II open fractures) requiring prolonged treatment with antibiotic were seen in each group. 2 case of shortening $>1 \mathrm{~cm}(9 \%)$ but $<2 \mathrm{~cm}$ was seen with stain less steel elastic nail and 2 cases of varus misalignment $>10^{\circ}(9 \%)$ was seen with stain less steel elastic nail. CONCLUSIONS: Our results indicate that that elastic nail can be effectively used to treat fractures of diaphysis of femur in children. It can also be used very effectively in open fractures (up to Gustilo \&Anderson grade II), in comminuted fractures (up to Winquist \& Hansen type II) and in a multisystem injured patient.

INTRODUCTION: Femoral shaft fractures are one of the common fractures in pediatric age group. They represent approximately $1.6 \%$ of all bony injuries in children. Males are affected more frequently than females. 
These fractures have bimodal age distribution with peak at 2 and 17 years. Fractures are mostly caused by fall during play (30\%) or abuse. Low velocity trauma leads to transverse fractures and high speed causes comminuted or segmental fractures.

The determination of ideal treatment of femoral shaft fracture in each child depends upon age of the child, the location and type of the fractures, the family environment, the knowledge and the ability and preferences of the surgeon, ${ }^{1}$ and to the lesser degree the financial implications. Below the age of 5 years, it is still a consensus to treat the child with fracture shaft femur conservatively as rapid healing and spontaneous correction of angulation takes place below this age group.,3

Near the end of skeletal maturity angular deformity is not correctable by growth, so, accurate reduction is necessary. ${ }^{4}$ Availability of locked intramedullary nail has made the treatment of femoral shaft fractures in skeletally matured children well established.

However, the best treatment between 5 and 14 years of age is a matter of debate. ${ }^{5}$ We know that the biomechanical properties of titanium are often considered to be superior to those of stainless steel for intramedullary fracture fixation and in vitro mechanical studies have demonstrated equal or superior fixation of pediatric femoral fractures with use of titanium elastic nails as compared with stainless steel elastic nails. ${ }^{6}$

So, the purpose of the present study is to evaluate the outcome of titanium and stainless steel elastic nail in paediatric femoral fractures in 5-14 years of age group. The perceived advantage of this technique includes- early union due to repeated micro motion at fracture site, respect for the physis, early mobilization, early weight bearing, scar acceptance, easy implant removal and high patient satisfaction rate.

MATERIAL AND METHODS: It is a prospective study which was conducted in the department of orthopedic surgery, GMC, Bhopal between June 2009 and October 2011. Essentially it was a study of 42 cases. Twenty children (16 boys, four girls) in the age group of 5-14 years (average 9.3 years) with femoral shaft fractures (16 closed, two Grade- I and two Grade- II compound) were stabilized with Titanium Elastic Nail (TEN),while twenty-two (16 boys, six girls) in the age group of 5-14 years (average 9.1 years) with femoral shaft fractures (18 closed, two Grade- I and two Grade- II compound) were stabilized with Stainless Steel Elastic Nail (SSEN) between June 2009 and October 2011. Grossly comminuted or multi fragmentary fractures (Winquist type III and IV comminuted fractures), Gustilo-Anderson type 3 open fractures, and pathological fractures were excluded from the study.

Most of the fractures were due to road traffic accidents $(n=14,63.6 \%$ in TEN group while $\mathrm{n}=16,72.7 \%$ in SSEN group). Right-sided involvement was seen in 12 cases (60\%) in TEN groups while that seen in 15 cases (68.2\%) in SSEN group and associated injuries were seen in four cases (10\%), two in each group. Five fractures were in the proximal third, 12 in the middle third and three were in the distal third for the TEN groups while six fractures were in the proximal third, 13 in the middle third and three were in the distal third for the SSEN group.

15 fractures were transverse, four minimally comminuted (Winquist I) and one were of Winquist type II in TEN group while 15 fractures were transverse, six minimally comminuted (Winquist I) and one were of Winquist type II in SSEN group. Majority of the patients $(n=17)$ underwent surgery within seven days of their injury. The surgery was performed under spinal anesthesia with the patient on the fracture table in supine position. 
Two Titanium Elastic Nails or Stainless Steel Elastic Nails of identical diameter were used. Use of the nail in patients were chosen according to the affordability of the patient (mainly) or availability of the implant at that moment. The diameter of the individual nail was selected as per Flynn et al's formula ${ }^{7}$ (Diameter of nail $=$ Width of the narrowest point of the medullary canal on Antero posterior and Lateral view x $0.4 \mathrm{~mm}$ ) and intraoperative assessment.

Fractures were reduced using fluoroscopic guidance. Nails were inserted in retrograde fashion with medial and lateral incision $2.5-3.5 \mathrm{~cm}$ above the physis. The nails were present sufficiently so that apex of the bowed nails rested at the same level on the fracture site to ensure a good equal recoil force. Open reduction was required in one case of TEN and two case of SSEN intraoperative due to soft tissue interposition and failure to push forward one nail to the proximal fragment.

The nails were driven proximally so that both were divergent and the tips got anchored minimum $1 \mathrm{~cm}$ distal to the physis. Postoperatively patients were nursed in supine position with the operated leg elevated on a pillow. Boot and bar was used in three cases (one in TEN groups, two in SSEN group) where fixation was thought not adequate. Patients were mobilized without weight bearing on the fifth to seventh day postoperatively. Partial weight bearing was started at three weeks and full weight bearing by six to eight weeks (in most of the cases) depending on the fracture configuration, callus response and associated injuries.

All patients were followed radio logically as well as clinically until fractures healed and for any complication. Measurements of angulation in the sagittal and coronal planes were done on antero posterior and lateral radiographs that were made immediately following surgery and following radiological union. Radiographs were also reviewed for evidence of healing, defined as bridged femoral cortices (three or four of four cortices) on antero posterior and lateral radiographs as per Anthony et al scale.1,8 Patients were followed up for an average period of 1 year 2 months.

The complications were classified as major or minor. Major complications were defined as conditions leading to unscheduled nail removal or operative treatment, including deep infection, implant irritation, or pain and nail breakage. ${ }^{9}$ Malunion, delayed union, and nonunion were considered to be major complications. Delayed union was defined as the persistence of bone pain and tenderness three months after the fracture without complete union radiographically. ${ }^{10}$

Nonunion was defined as the absence of osseous union more than six months after the injury. ${ }^{10}$ Malunion was defined as an angulation of $>5^{\circ}$ in the coronal plane or $>10^{\circ}$ in the sagittal plane. Minor complications were defined as nail irritation or infection that was treated nonoperatively ${ }^{9}$. The results were evaluated using Flynn et al's scoring criteria ${ }^{11}$ for both TEN and SSEN group. Nails were removed six to eight months post-surgery when the fracture line was no longer visible radiologically.

RESULTS: The median duration of surgery was $60 \mathrm{~min}(40-100 \mathrm{~min})$ in both the groups. The mean hospital stay was 9.4 days in TEN group and 9.6 days in SSEN group (3-20 days). The hospital stay was dictated by associated injuries and the adequacy of fixation. All 42 patients were available for evaluation after a mean of 14 months (6-20 months) of follow up. Radiological union was achieved in all cases in a mean time of 7.7 weeks (6-12 weeks) in TEN groups while that took 7.9 weeks in SSEN group. Full weight bearing was possible in a mean time of 7.7 weeks (6-12 weeks) in TEN group and a mean of 7.9 weeks in SSEN group. 
All cases were assessed by Flynn classification method and outcome scoring system. We noted excellent results in 26 cases (63\%), satisfactory results in 14 cases (33\%), while poor result in 2 cases (4\%) in this study. This is quite similar to study conducted by Flynn et al (2001) who noted excellent results in 38 cases (65.5\%), satisfactory results in 18 cases (31.03\%), and poor result in 1 case $(1.7 \%)$.

The results were excellent in 14 patients (70\%), satisfactory in six (30\%) and poor in none as per the scoring criteria for TEN by Flynn et al. In the SSEN group, results were excellent in 12 patients (54.5\%), satisfactory in $8(36.36 \%)$ and poor in $2(9.1 \%)$ patients using same criteria.

There were six minor complications in the stainless steel group, including one case of superficial cellulitis that was treated with antibiotics and one case of implant-related pain that was treated with analgesics and four cases of skin irritation at the nail tip (18\%) in this group while 1 case (5\%) of such incidence occurred with titanium nail.

Leaving nail end long ( $>2 \mathrm{~cm}$ ) and untrimmed was significantly associated with entry site irritation. 2 cases deep infection (both cases are associated with grade II open fractures) requiring prolonged treatment with antibiotic were seen in each group. 2 case of shortening $>1 \mathrm{~cm} \mathrm{(9 \% )} \mathrm{but}$ $<2 \mathrm{~cm}$ was seen with stain less steel elastic nail and 2 cases of varus mal alignment $>10^{\circ}(9 \%)$ was seen with stain less steel elastic nail while no such incidence was observed with titanium nail.

Total major complication rate with stain less steel elastic nail was (18\%) while that with titanium nail was none. No cases of delayed union, non-union re fracture, nail breakage, premature removal of nails due to nail entry site irritation was seen during the whole study in any of the group.

\begin{tabular}{|c|c|c|c|}
\hline Fracture pattern & Excellent & Satisfactory & Poor \\
\hline Winquist and Hansen type 0 & 22 & 12 & 0 \\
\hline Winquist and Hansen type 1 & 4 & 2 & 0 \\
\hline Winquist and Hansen type 2 & 0 & 0 & 2 \\
\hline
\end{tabular}

SHOWING CORRELATION OF FRACTURE TYPE WITH FUNCTIONAL OUTCOME

\begin{tabular}{|c|c|c|c|}
\hline Fracture pattern & Excellent & Satisfactory & Poor \\
\hline Gustilo and Anderson Grade 1 & 4 & 0 & 0 \\
\hline Gustilo and Anderson Grade 2 & 2 & 2 & 0 \\
\hline
\end{tabular}

DISCUSSION: The use of elastic stable intramedullary nailing for the treatment of pediatric femoral shaft fractures is based on the principles of elastic stability and balanced forces (achieved by using the nails of the same diameter).

This technique also provides certain advantages such as early union due to repeated micro motion at fracture site, respect for the physis, early mobilization, early weight bearing, scar acceptance, minimally invasive surgery, freedom from pre selection of proper implant length (any excess nail length is cut off), easy implant removal and high patient satisfaction rate and the fact that no power instrument is required for implant insertion. ${ }^{1,12,13,14}$

The cited advantages of titanium include a lower modulus of elasticity in comparison with stainless steel, biocompatibility, Osseo integration, and magnetic resonance imaging compatibility, whereas titanium is more notch-sensitive and has fatigue strength less than that of stainless steel. ${ }^{15,18}$ 
It has been suggested that the lower modulus of elasticity of titanium as compared with stainless steel makes titanium nails ideal for use in children.14,19,21 Mahar et al ${ }^{19}$ showed better fracture stability in association with titanium nails as compared with stainless steel nails on torsional and axial compression testing, whereas Mani et al ${ }^{20}$ showed no significant difference in fracture stability between stainless steel and titanium nails on bending, torsion, and axial compression testing.

The patients between the age group of 5-14 years were included in this study. This age group was selected because patients between the age group of 5-14 years spontaneous correction of angular misalignment occur only slightly.22 Also problems like knee stiffness, shortening occurred in children above 5 years who were treated with conservative methods. ${ }^{23}$ Children below age of 5 years can well tolerate traction, prolonged bed rest and immobilization without any significant adverse social or functional sequel.

Also anatomical reduction is usually not necessary as deformities tend to correct with growth in cases of young children. ${ }^{23}$ Children above this age group are treated as adults with rigid intramedullary rod fixation. ${ }^{25}$ The age range of patients included in this study was almost similar to that of Hossam. M. Kandil (2007) where age range was 4.9-13.2 years and Navdeep Singh et al (2010) where age range was6-14 years. ${ }^{25}$ The patients included in study by Flynn et al (2001) were in the age range of $4-16$ years.

Limitation of the present study is that the patients were not randomly assigned to treatment groups. Also, in the present study, we use of the same cutoff criteria for malunion for patients of all ages as per Flynn's outcome criteria. Had we used different cutoff criteria for different age group, results may a bit different from the present findings. But with the application of the uniform malunion criteria across all age groups, there was no increase in the femoral malunion rate with increasing age or weight in the present study of children ranging in age from to 5-14 years.

Flynn et al (2001) stated that the ideal device to treat pediatric femur fractures would be a simple, load sharing internal splint allowing mobilization and maintenance of alignment for a few weeks until bridging callus forms. The device would exploit a child's denser bone, rapid healing, and ability to remodel, without risking the physis or blood supply to the femoral head.

Thus the aim to fix fractures of diaphysis of femur in children with intramedullary nails is to encourage formation of bridging periosteal callus. Elastic intramedullary nailing provides a combination of elastic mobility (as these nails allows micro motion at the fracture site) and stability. The treatment of the pediatric femur fracture, however continue to evolve. For many reasons, the adolescent group poises a great challenge to the treating surgeons.

The traditional method of traction and spica casting can be effective but is more difficult in older children due to their size, slower healing rate, and limited potential for remodeling. Operative stabilization can simplify management but carries the attendant risks of surgery, particularly injury to functioning physis.

The use of elastic nail in fracture of shaft of femur of children has expanded the treatment options for patients with multi skeletal or multisystem injuries especially head injury patients where nursing care with conservative treatment is quite cumbersome. Kirk Fry et.al (1976) ${ }^{26}$ evaluated children with fracture shaft femur with head injury and found operative management to be safe and effective method for management of these fractures. In patients with multiple fractures, simultaneous fracture fixation in more than one limb may be desirable. 
Elastic nailing is done in supine position over fracture table, thus allowing simultaneous procedure for upper limb and other systems. Where there is an indication of life saving procedures, such as craniotomy or laprotomy, repositioning of the patient is not necessary for subsequent fracture fixation.

CONCLUSION: Hence, from our study, it can be concluded that elastic nail can be effectively used to treat fractures of diaphysis of femur in children. It can also be used very effectively in open fractures (up to Gustilo \&Anderson grade II), in comminuted fractures (up to Winquist \&Hansen type II), in a multisystem injured patient. Even proximal third and distal third fractures can be fixed with excellent to satisfactory results in most of the cases.

It leads to rapid bone healing and non-interference to fracture hematoma and minimal periosteal stripping. The load sharing mechanism of intramedullary nailing promotes secondary bone healing. This procedure provides the stable fracture fixation and allows the early mobilization and early rehabilitation of patients. It reduces the hospitalization time while achieving near anatomic alignment, maintaining length and allowing early active motion at the hip and knee.

\section{REFERENCES:}

1. Narayanan UG, Hyman JE, Wainwright AM, Rang M, Alman BA. Complications of elastic stable intramedullary nail fixation of pediatric femoral fractures and How to avoid them. J Pediatr Orthop 2004; 24: 363-9.

2. Buckley SL. Current trends in the treatment of femoral shaft fractures in children and adolescents. Clin Orthop Relat Res 1997; 338: 60-73.

3. Gwyn DT, Olney BW, Dart BR, Czuwala PJ. Rotational control of various pediatric femur fractures stabilized with Titanium Elastic Nails. J Pediatr Orthop 2004; 24: 172-7.

4. Metaizeau JP. Stable elastic nailing for fractures of the femur in children. J Bone Joint Surg Br 2004; 86: 954-7.

5. Flynn JM, Luedtke LM, Theodore J, Ganley TJ, Dawson J, Davidson RS, et al . Comparison of titanium elastic nails with traction and a spica cast to treat femoral fractures in children. J Bone Joint Surg Am 2004; 86: 770-7.

6. Eric J. Wall, Viral Jain, Vagmin Vora, Charles T. Mehlman, Alvin H. Crawford. Complications of Titanium and Stainless Steel Elastic Nail Fixation of Pediatric Femoral Fractures the Journal of Bone \& Joint Surgery. 2008; 90: 1305-1313.

7. Flynn JM, Skaggs DL, Sponseller PD, Ganley TJ, Kay RM, Kellie Leitch KK. The operative management of pediatric fractures of the lower extremity. J Bone Joint Surg Am 2002; 84: 2288300.

8. Hassan Al-Sayed, M.D. Titanium Elastic Nail Fixation for Paediatric Femoral Shaft Fractures; pan arab journal of ortho trauma; vol 10,no.1,January 2006.

9. Sink EL, Gralla J, Repine M. Complications of pediatric femur fractures treated with titanium elastic nails: a comparison of fracture types. J Pediatr Orthop.2005; 25: 577-80.25577 2005.

10. Luhmann SJ, Schootman M, Schoenecker PL, Dobbs MB, Gordon JE. Complications of titanium elastic nails for pediatric femoral shaft fractures. J Pediatr Orthop.2003; 23: 443-7.23443 2003. 


\section{ORIGINAL ARTICLE}

11. Flynn JM, Hresko T, Reynolds RA, Blasier RD, Davidson R, Kasser J. Titanium elastic nails for pediatric femur fractures: A multicenter study of early results with analysis of complications. J Pediatr Orthop 2001; 21: 4-8.

12. Ligier JN, Metaizeau JP, Prévot J, Lascombes P. Elastic stable intramedullary nailing of femoral shaft fractures in children. J Bone Joint Surg Br.1988; 70: 74-7.7074 1988.

13. Bhaskar A. Treatment of long bone fractures in children by flexible titanium nails. Indian J Orthop 2005; 39: 166-8.

14. Hunter JB. The principles of elastic stable intramedullary nailing in children. Injury 2005; 36 : A20-4.

15. Arens S, Schlegel U, Printzen G, Ziegler WJ, Perren SM, Hansis M. Influence of materials for fixation implants on local infection. An experimental study of steel versus titanium DCP in rabbits. J Bone Joint Surg Br.1996; 78: 647-51.78647 1996.

16. Kitsugi T, Nakamura T, Oka M, Yan WQ, Goto T, Shibuya T, Kokubo T, Miyaji S. Bone bonding behavior of titanium and its alloys when coated with titanium oxide (TiO2) and titanium silicate (Ti5Si3). J Biomed Mater Res.1996; 32: 149-56.32149 1996.

17. Uhthoff HK, Bardos DI, Liskova-Kiar M. The advantages of titanium alloy over stainless steel plates for the internal fixation of fractures. An experimental study in dogs. J Bone Joint Surg Br. 1981; 63: 427-84.63427 1981.

18. Skripitz R, Aspenberg P. Tensile bond between bone and titanium: a reappraisal of osseointegration. Acta Orthop Scand.1998; 69: 315-9.69315 1998.

19. Mahar AT, Lee SS, Lalonde FD, Impelluso T, Newton PO. Biomechanical comparison of stainless steel and titanium nails for fixation of simulated femoral fractures. J Pediatr Orthop.2004; 24: 638-41.246382004.

20. Mani US, Sabatino CT, Sabharwal S, Svach DJ, Suslak A, Behrens FF. Biomechanical comparison of flexible stainless steel and titanium nails with external fixation using a femur fracture model. J Pediatr Orthop.2006; 26: 182-7.26182 2006.

21. Disegi JA. Titanium alloys for fracture fixation implants. Injury.2000; 31 Suppl 4: 14-7.3114 2000.

22. Kissel, E. U., Miller, M.E. Closed Ender Nailing of Fractures in Older Children J. Trauma. 1989, 29: pp 1585-1588.

23. Mann D, Weddington J, Davenport K. Closed Ender Nailing of Femoral Shaft Fractures in Adolescents. J Pediatr Orthop. 1986, 6: 651-655.

24. Hossam M. Kandil; Titanium Flexible Intramedullary Nailing INI MEDICAL JOURNAL VOL. 13, NO 3, May 200745 of Pediatric Femoral Shaft Fractures.

25. Herndon, W.A. Mahnken R, Yngve D, Sullivan A. Management of femoral fractures in the adolescent. J Pediatr Orthop. 1989, 9: 29-32.

26. Fry, K.; Hoffer, M; Brink, J.: Femoral shaft fractures in brain injured children. J. Trauma. 


\section{ORIGINAL ARTICLE}
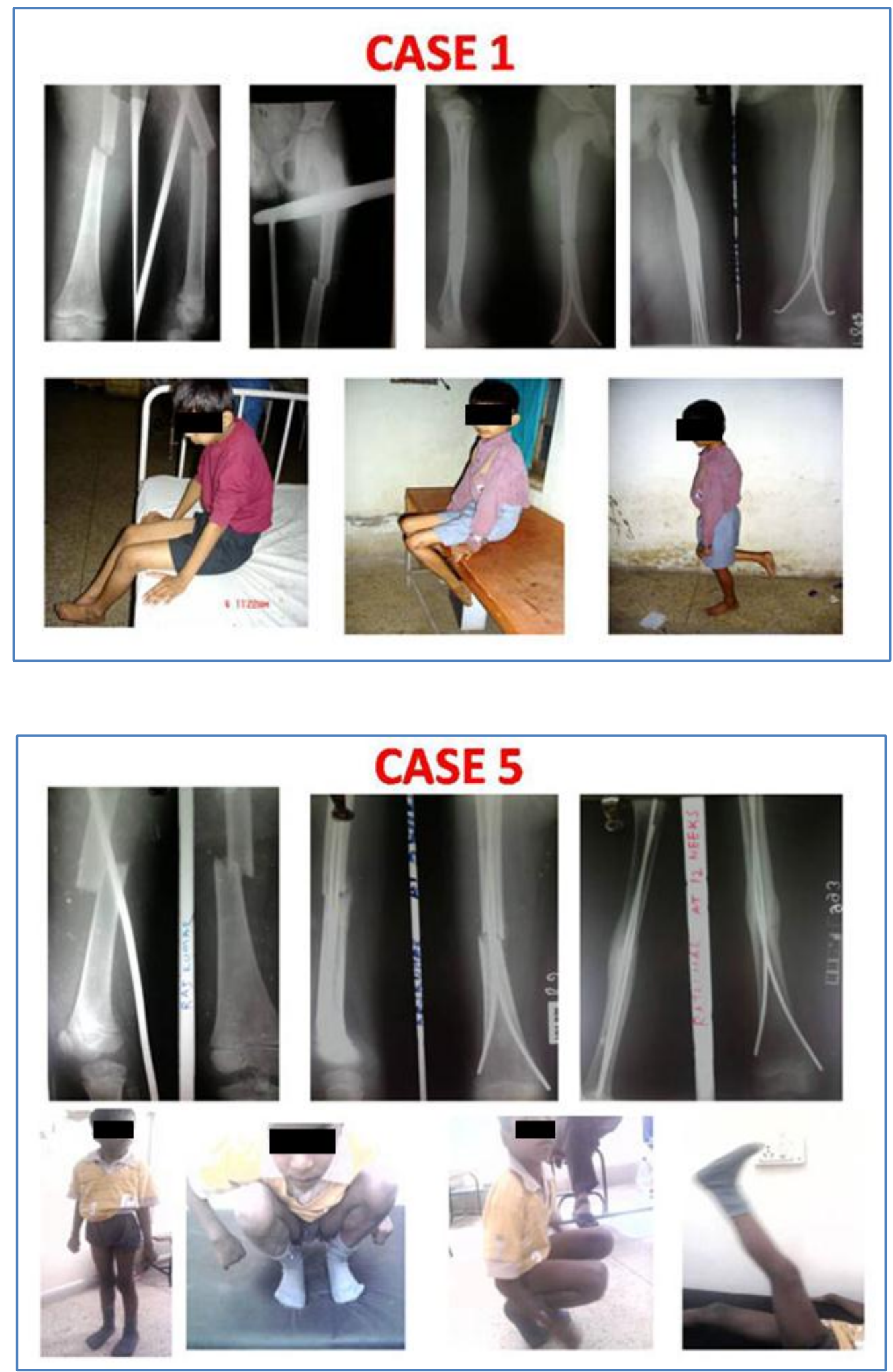


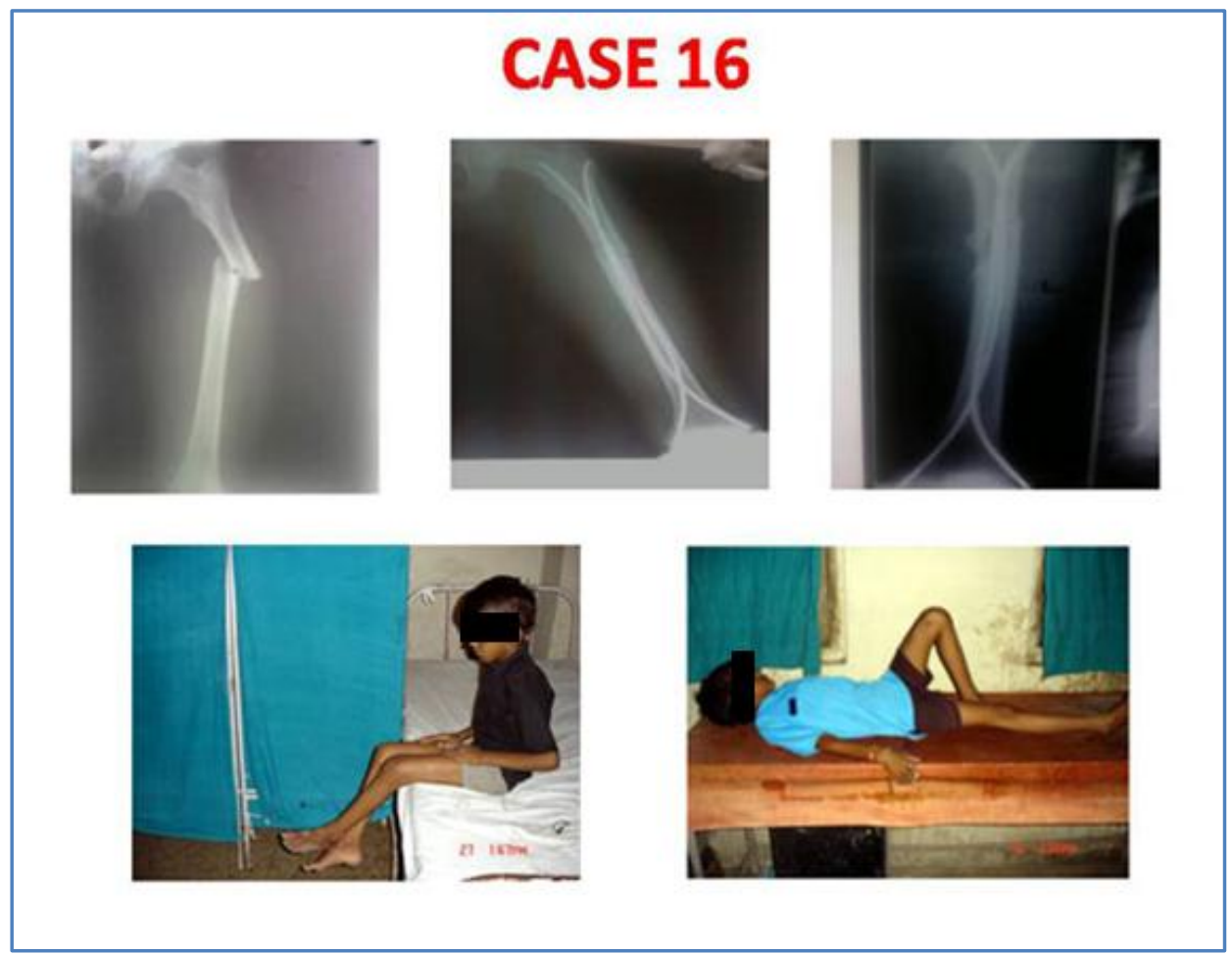

\section{AUTHORS:}

1. Saubhik Ray

2. Ashish Goyal

3. Ashish Gohiya

4. Sanjeev Gaur

\section{PARTICULARS OF CONTRIBUTORS:}

1. Senior Resident, Department of Orthopaedics, ESIC Medical College and Hospital, Joka, Kolkata.

2. Senior Resident, Department of Orthopaedics, MGM Medical College, Indore M. P.

3. Associate Professor, Department of Orthopeadics, Gandhi Medical College, Bhopal.

4. Professor \& HOD, Department of Orthopaedics, Gandhi Medical College, Bhopal.

Date of Submission: 18/08/2014. Date of Peer Review: 19/08/2014. Date of Acceptance: 09/09/2014. Date of Publishing: 12/09/2014. 